\title{
Update Breast Cancer 2021 Part 1 - Prevention and Early Stages
}

\author{
Update Mammakarzinom 2021 Teil 1 - \\ Prävention und frühe Krankheitsstadien
}

\section{(이 (1) (2) $\Theta$}

\section{Authors}

Elmar Stickeler ${ }^{1}$, Bahriye Aktas ${ }^{2}$, Annika Behrens ${ }^{3}$, Erik Belleville ${ }^{4}$, Nina Ditsch ${ }^{5}$, Peter A. Fasching ${ }^{3}$, Tanja N. Fehm ${ }^{6}$, Andreas D. Hartkopf ${ }^{7}$, Christian Jackisch ${ }^{8}$, Wolfgang Janni ${ }^{9}$, Cornelia Kolberg-Liedtke ${ }^{10}$, Hans-Christian Kolberg ${ }^{11}$, Diana Lüftner ${ }^{12}$, Michael P. Lux ${ }^{13}$, Volkmar Müller ${ }^{14}$, Andreas Schneeweiss ${ }^{15}$, Florian Schütz ${ }^{16}$, Carla E. Schulmeyer ${ }^{3}$, Hans Tesch ${ }^{17}$, Christoph Thomssen ${ }^{18}$, Christoph Uleer ${ }^{19}$, Michael Untch ${ }^{20}$, Manfred Welslau ${ }^{21}$, Achim Wöckel ${ }^{22}$, Lena A. Wurmthaler ${ }^{3}$, Rachel Würstlein ${ }^{23}$, Marc Thill ${ }^{24}$

Affiliations

1 Department of Gynecology and Obstetrics, RWTH University Hospital Aachen, Aachen, Germany

2 Klinik und Poliklinik für Gynäkologie, Universitätsklinikum Leipzig, Leipzig, Germany

3 Erlangen University Hospital, Department of Gynecology and Obstetrics, Comprehensive Cancer Center ErlangenEMN, Friedrich-Alexander University Erlangen-Nuremberg, Erlangen, Germany

4 ClinSol GmbH \& Co. KG, Würzburg, Germany

5 Department of Gynecology and Obstetrics, University Hospital Augsburg, Augsburg, Germany

6 Department of Gynecology and Obstetrics, University Hospital Düsseldorf, Düsseldorf, Germany

7 Department of Obstetrics and Gynecology, University of Tübingen, Tübingen, Germany

8 Department of Obstetrics and Gynecology, Sana Klinikum Offenbach, Offenbach, Germany

9 Department of Gynecology and Obstetrics, Ulm University Hospital, Ulm, Germany

10 Department of Gynecology and Obstetrics, University Hospital Essen, Essen, Germany

11 Department of Gynecology and Obstetrics, Marienhospital Bottrop, Bottrop, Germany

12 Charité University Hospital, Department of Hematology, Oncology and Tumour Immunology, University Medicine Berlin, Berlin, Germany

13 Klinik für Gynäkologie und Geburtshilfe, Frauenklinik St. Louise, Paderborn, St. Josefs-Krankenhaus, Salzkotten, Germany

14 Department of Gynecology, Hamburg-Eppendorf University Medical Center, Hamburg, Germany

15 National Center for Tumor Diseases (NCT), Heidelberg University Hospital and German Cancer Research Center, Heidelberg, Germany
16 Gynäkologie und Geburtshilfe, Diakonissen-StiftungsKrankenhaus Speyer, Speyer, Germany

17 Oncology Practice at Bethanien Hospital Frankfurt, Frankfurt, Germany

18 Department of Gynaecology, Martin-Luther-University Halle-Wittenberg, Halle (Saale), Germany

19 Praxisgemeinschaft Frauenärzte am Bahnhofsplatz, Hildesheim, Germany

20 Clinic for Gynecology and Obstetrics, Breast Cancer Center, Genecologic Oncology Center, Helios Klinikum Berlin Buch, Berlin, Germany

21 Onkologie Aschaffenburg, Aschaffenburg, Germany

22 Department of Gynecology and Obstetrics, University Hospital Würzburg, Würzburg, Germany

23 Breast Center, Department of Gynecology and Obstetrics and CCC Munich LMU, LMU University Hospital, Munich, Germany

24 Agaplesion Markus Krankenhaus, Department of Gynecology and Gynecological Oncology, Frankfurt, Germany

Key words

early breast cancer, prevention, treatment, prognosis, immunotherapy, digital medicine

Schlüsselwörter frühes Mammakarzinom, Prävention, Therapie, Prognose, Immuntherapie, digitale Medizin

received

accepted after revision

23.3. 2021

published online

3. 5.2021

Bibliography

Geburtsh Frauenheilk 2021; 81: 526-538

DOI 10.1055/a-1464-0953

ISSN 0016-5751 
(c) 2021. The Author(s).

This is an open access article published by Thieme under the terms of the Creative Commons Attribution-NonDerivative-NonCommercial-License, permitting copying and reproduction so long as the original work is given appropriate credit. Contents may not be used for commercial purposes, or adapted, remixed, transformed or built upon. (https://creativecommons.org/licenses/by-nc-nd/4.0/)

Georg Thieme Verlag KG, Rüdigerstraße 14,

70469 Stuttgart, Germany

\section{Correspondence}

Peter A. Fasching, MD

Erlangen University Hospital, Department of Gynecology and Obstetrics, Comprehensive Cancer Center Erlangen EMN,

Friedrich Alexander University of Erlangen-Nuremberg

Universitätsstraße 21-23, 91054 Erlangen, Germany

peter.fasching@fau.de

Deutsche Version unter:

https://doi.org/10.1055/a-1464-0953

\section{ABSTRACT}

This review summarises not only the latest evidence on prevention, but also the current research on the treatment of early-stage breast cancer patients. Recent years have seen a growing body of evidence on the risk of high- and moderatepenetrance breast cancer susceptibility genes. A large international consortium has now been able to further refine the answer to the question of the significance of the so-called panel genes. Moreover, the data on treatment selection regarding endocrine efficacy and the decision for or against chemotherapy have also been advanced markedly. There is also new data on adjuvant CDK4/6 (cyclin-dependent kinase 4/ 6) inhibitors, which are standard in first-line treatment in patients with metastatic HER2-negative, hormone receptor-positive $(\mathrm{HR}+)$ breast cancer. For other therapies such as immune checkpoint inhibitors, which have successfully improved the rate of pathologic complete response (PCR) in neoadjuvant treatment settings for patients with triple-negative breast cancer (TNBC), there is a growing understanding of the quality of life and side effects. This is especially important in situations where patients could possibly be cured without such a regimen.

\section{ZUSAMMENFASSUNG}

In dieser Übersichtsarbeit werden nicht nur die neuesten Erkenntnisse zur Prävention, sondern auch die aktuellen Arbeiten zur Behandlung von Mammakarzinompatientinnen im frühen Krankheitsstadium zusammengefasst. In den letzten Jahren haben sich die Hinweise über hoch-penetrante und mittelgradig penetrante Risikogene für ein Mammakarzinom verdichtet. Nun konnte in einem großen internationalen Konsortium die Antwort auf die Frage nach der Wertigkeit der sogenannten Panelgene weiterentwickelt werden. Des weiteren sind auch die Daten zur Therapieselektion in Bezug auf endokrine Wirksamkeit und die Entscheidung für oder gegen eine Chemotherapie deutlich weiterentwickelt worden. Ebenso gibt es neue Daten zum adjuvanten Einsatz von CDK4/6-(Cyclin-dependent-kinase-4/6-)Inhibitoren, die in der 1. Therapielinie für Patientinnen mit metastasiertem HER2-negativem, hormonrezeptorpositiven ( $\mathrm{HR}+)$ Mammakarzinom zum Therapiestandard gehören. Bei anderen Therapien wie den Immuncheckpoint-Inhibitoren, welche erfolgreich in der neoadjuvanten Therapiesituation bei Patientinnen mit einem triple-negativen Mammakarzinom (TNBC) die Rate an pathologischen Komplettremissionen ( $P C R$ ) verbessern konnten, wächst das Verständnis für Lebensqualität und Nebenwirkungen. Dies ist von besonderer Bedeutung in einer Situation, in der Patientinnen potenziell auch ohne eine solche Therapie geheilt werden könnten.

\section{Introduction}

This review summarises the latest study outcomes in prevention and treatment of patients with early-stage breast cancer. Developments in recent years have shown that treatment innovations enter clinical practice at a rapid pace [1-6]. This paper includes full publications and presentations at the current major cancer and breast cancer meetings such as ESMO (European Society for Medical Oncology) 2020 and SABCS (San Antonio Breast Cancer Symposium) 2020. During the COVID-19 pandemic, these meetings were largely held in a virtual setting. Due to the pandemic, it is not just medical communication that has suffered. Far more significant is the drop in patient participation in screening and diagnostic procedures, the restrictions on planned interventions and procedures with medical indications, as well as the resulting decline in the patients' quality of life.

\section{Prevention}

\section{Panel gene knowledge deepens}

All inherited genetic risk factors can explain about $40 \%$ of a twofold increased familial risk of breast cancer [7-9]. Risk genes are divided into those with high, moderate and low penetrance. These largely comprise common polymorphisms for which over $150 \mathrm{ge}$ nomic regions have been identified [10-27]. BRCA1/2 accounts for about $16 \%$ and low-penetrance genes for about $18 \%$ of this familial risk [28]. Medium penetrance genes could explain about $4 \%$ of the twofold increase in familial risk [28]. Often these genes were included in so-called gene panels evaluated as part of genetic counselling and testing (e.g., PALB2, ATM, CHEK2, ...). This has been the subject of much discussion in recent years and studies have been undertaken to quantify the risk of these genes [29, 30]. As is also evident from - Fig. $\mathbf{1}$, in both papers the lifetime risk of moderate-penetrance risk genes was lower than for $B R C A 1$ or BRCA2 (except PALB2) [31,32]. In over 60000 female breast 


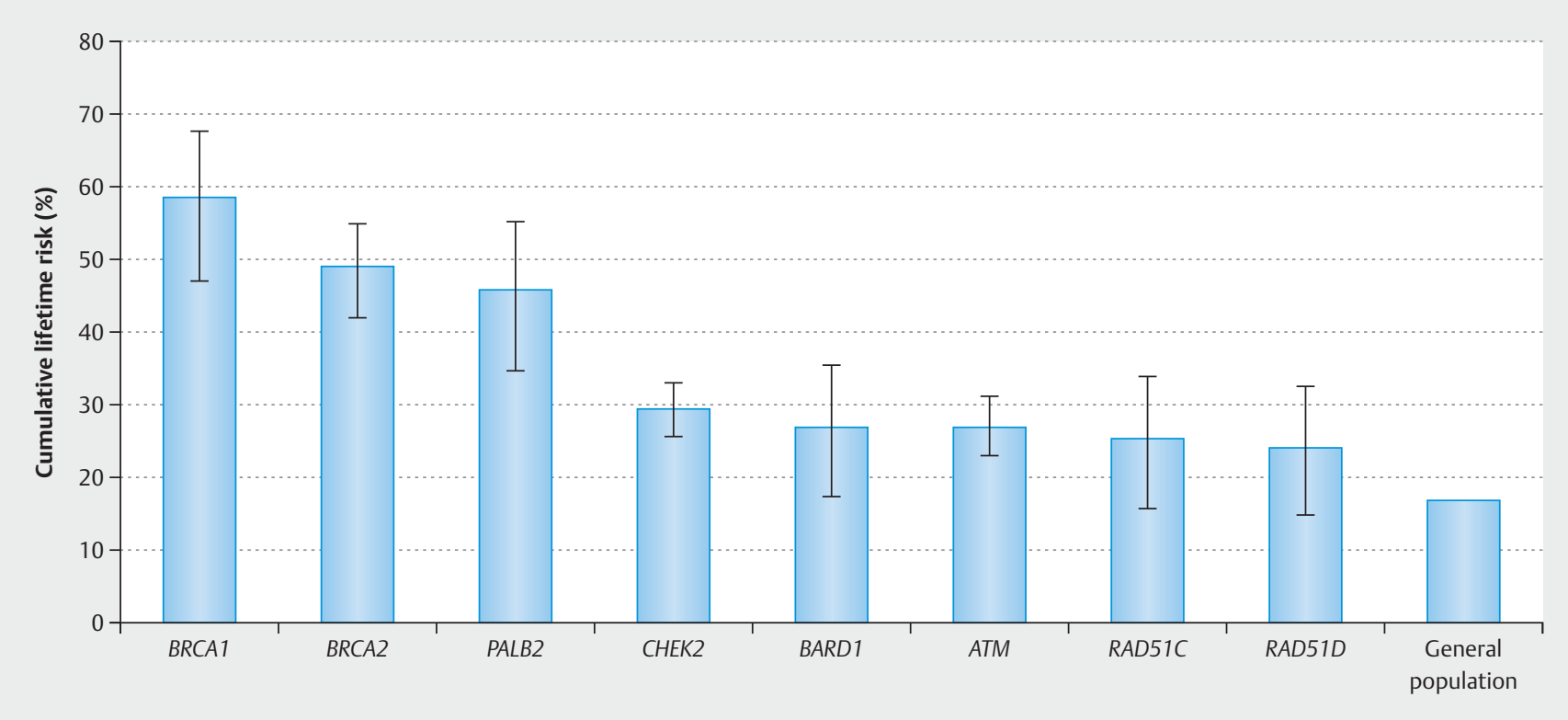

- Fig. 1 Lifetime risk up to 80 years of age for the eight confirmed risk genes according to [31].

cancer patients and more than 53400 healthy controls, 34 putative risk genes were sequenced and screened for protein truncating mutations and rare missense mutations [31]. The genes studied are listed in $>$ Table 1. ATM, BRCA1, BRCA2, CHEK2, and PALB2 clearly correlated with an increased risk of breast cancer. BARD1, RAD51C, RAD51D, and TP53 also correlated with breast cancer risk, but not as markedly as those noted above. > Fig. 1 presents the cumulative lifetime risks according to Dorling et al. up to the age of 80 years. It becomes clear that in the risk range 45-60\% BRCA1, BRCA2 and PALB2 together should be classified as high-penetrance risk genes, while the other confirmed risk genes with lifetime risks of $20-30 \%$ may be regarded as moderate risk genes. Ultimately, this paper, with more than 110000 patients, provides the foundation for risk counselling. Even though no significant correlation was found for the remaining genes, this does not imply that they are not risk genes, but only that in this study design they did not attain risk ranges comparable to these eight confirmed genes. The role of these risk genes in the treatment of breast cancer is unclear. While carriers of the BRCA1/2 mutation respond better to chemotherapy or PARP (poly-[ADP-ribose]polymerase) inhibitors [33-38] in the neoadjuvant setting and to PARP inhibitors when metastasis is present [39-41], for the other mutations evidence that patients have a good chance of responding to olaparib therapy could only be found for PALB2 [42].

\section{Impact of diet and microbiome on breast cancer risk}

It has already been established in some epidemiological studies that body weight impacts on the risk of breast cancer. Interestingly enough, in premenopausal women, a high BMI (body mass index) does not appear to be associated with increased risk. In postmenopausal women, on the other hand, a high BMI correlates with an increased risk of breast cancer [43-45]. Moreover, there seem to be other metabolic factors affecting the risk of breast
- Table 1 The risk genes studied in over 60000 breast cancer patients and more than 53400 healthy controls.

\begin{tabular}{|c|c|c|c|}
\hline ABRAXIS1 & CHEK $^{1}{ }^{1}$ & MSH6 & RAD50 \\
\hline AKT1 & EPCAM & MUTYH & RAD51C ${ }^{2}$ \\
\hline ATM $^{1}$ & FANCC & $N B N$ & $R A D 51 D^{2}$ \\
\hline BABAM2 & FANCM & NF1 & RECQL \\
\hline${\text { BARD } 1^{2}}^{2}$ & GEN1 & PALB2 $^{1}$ & RINT1 \\
\hline BRCA1 ${ }^{1}$ & MEN1 & PIKЗСA & STK11 \\
\hline BRCA2 $^{1}$ & MLH1 & PMS2 & TP532 \\
\hline BRIP1 & MRE11 & PTEN & $X R C C 2$ \\
\hline $\mathrm{CDH} 1$ & MSH2 & & \\
\hline
\end{tabular}

${ }^{1}$ Breast cancer risk correlation with a $\mathrm{p}$-value $<0.0001$

${ }^{2}$ Breast cancer risk correlation with a p-value $<0.05$

bold $=$ confirmed breast cancer risk genes with high or moderate penetrance

cancer independently of BMI [43]. With regard to prognosis, it has also been established that obesity has a negative effect on the course of the disease and the molecular subtype $[46,47]$ This suggests a link between metabolism and breast cancer risk with more complex mechanisms. One study looking into this is the cohort study "NutriNet-Santé" [48]. It investigated the possible correlation between a high glycaemic index (a measure of the hyperglycaemic effect of food containing carbohydrates) and high glycaemic load with an increased risk of breast cancer. In the study, which was controlled by online questionnaires, more than 171000 respondents were questioned every 6 months about diet and lifestyle, among other things. Over 81000 women were evaluated in quintiles regarding the topic. 927 breast cancer cases 
were observed. It was shown that unlike postmenopausal women in the lowest quintile of glycaemic load those in the highest quintile were at a significantly higher risk of breast cancer with a hazard ratio of 1.64 (95\% Cl: 1.06-2.55). Similarly, compared with the bottom quintile the share of diet with moderate and high glycaemic index in the top quintile correlated with an increased risk of breast cancer in pre- and postmenopausal women $(H R=1.48$; $95 \% \mathrm{Cl}: 1.18-1.86)$ [48]. This study thus revealed that the composition of the diet can affect the risk of breast cancer. Since the analysis included BMI, height, physical activity, and other confounders as well, it can also be stated that this risk from diet is independent of these other parameters.

In the past, the gut microbiome has already been linked to the efficacy of immunotherapy in cancer patients [49]. The association between gut microbiome and breast cancer risk has also been studied [50] by now based on an existing large case-control study of over 130000 breast cancer cases and more than 110000 controls [51]. Moreover, studies were included that had investigated the correlation between genetic variants and the presence of specific microbiome patterns [52]. The 13 genetic variants correlating with specific microbiome patterns [52] were then studied by Mendelian randomisation for their correlation with breast cancer risk in the large case-control study [51]. In the overall population, the bacterial genus ruminococcus was identified as a risk factor. In triple-negative breast cancer (TNBC), bacteria of the genus parabacteroides have been identified as protective and unclassified bacteria of the order bacteroidales as risk factors [50]. However, as the interaction between health and the microbiome is not yet fully understood, it is difficult to establish a risk-reducing interventional strategy based on this data.

\section{Neoadjuvant Therapy}

\section{Neoadjuvant treatment in patients with hormone receptor-positive HER2-negative tumours}

Although pathologic complete response ( $\mathrm{pCR}$ ) generally predicts good outcome after neoadjuvant chemotherapy, this effect is most pronounced in patients with HER2-positivity or TNBC [5357]. In patients with HR+/HER2- tumours, the interaction is less evident, which is why understanding resistance mechanisms in the neoadjuvant setting is of particular clinical relevance. An important clinical issue is whether chemotherapy is associated with a benefit in endocrine resistance or endocrine sensitivity. Ki-67 and multigene tests would seem to be promising biomarkers in this setting. The response to endocrine treatment resulting in $\mathrm{Ki}$ 67 decline within a few weeks was a significant prognostic marker, e.g. in the POETIC trial [58].

\section{Absence of Ki-67 response under endocrine therapy and subsequent neoadjuvant chemotherapy}

ALTERNATE is a new trial looking at these mechanisms. In this trial HER2-/HR+ patients with elevated Ki-67 levels persistently $>10 \%$ after initial neoadjuvant endocrine therapy underwent neoadjuvant chemotherapy. Data has been reported from this arm regarding the neoadjuvant chemotherapy [59]. Of the 1299 patients enrolled in the trial, 286 patients had a Ki-67 level $>10 \%$ after renewed core needle biopsy under neoadjuvant endocrine therapy. 168 of these 286 patients underwent neoadjuvant chemotherapy, while the remaining patients were operated on directly. 14 patients with neoadjuvant treatment did not undergo surgery. Only 8 patients (4.8\%; 95\% Cl: $2.1-9.2$ ) achieved a pCR, despite the fact that more than $80 \%$ of the tumours tested Ki- 67 $>20 \%$ [59]. In another trial in which the Ki-67 level was established before chemotherapy, the pCR rate in Ki-67 of 20\% was a similar $8 \%$ [55]. Whether re-biopsy under endocrine therapy can provide more information than the initial Ki-67 level should be investigated further. The results of this trial cannot be applied in clinical practice when deciding for or against neoadjuvant chemotherapy or initial surgery.

Also in the ADAPT study HR+ HER2- patients were selected for a neoadjuvant chemotherapy based on a multigene test (OncotypeDX ${ }^{\circledR}$ ) and a Ki-67 assessment after a 3-week endocrine treatment [60]. Eligible for neoadjuvant chemotherapy were patients with a recurrence score of $>25$ or more than 3 positive lymph nodes and patients with $>10 \% \mathrm{Ki}-67$ positive cells in the repeat core needle biopsy 3 weeks after endocrine treatment [60]. Patients were randomised into one of two arms: 4 cycles of paclitaxel $175 \mathrm{mg} / \mathrm{m}^{2}$ every 2 weeks followed by 4 cycles of epirubicin/cyclophosphamide every 2 weeks versus 8 cycles of Nab-paclitaxel $125 \mathrm{mg} / \mathrm{m}^{2}$ weekly followed by 4 cycles of epirubicin/cyclophosphamide every 2 weeks. In the paclitaxel arm, the pCR rate was $12.9 \%$ and in the Nab-paclitaxel arm 20.8\% ( $p=0.002)$ [60]. Thus, after demonstrating better efficacy of Nab-paclitaxel versus paclitaxel in the neoadjuvant treatment of TNBC patients [61], it has now also been shown in HER2-, HR+ patients that the PCR rate could be almost doubled [61]. These outcomes confirm the pCR results of the GeparSepto trial in triple negative patients [62]. This trial also demonstrated a significant effect on metastasis-free survival [61].

\section{Survival analysis update of the KEYNOTE-522 trial}

The data from the third interim analysis (IA3) of the KEYNOTE-522 trial was presented at a meeting of the Oncologic Drugs Advisory Committee (ODAC) at the US Food and Drug Administration (FDA). This analysis was based on a total of 174 events. The hazard ratio was 0.65 ( $95 \% \mathrm{Cl}$ : 0.48-0.88; $\mathrm{p}=0.0025)$. However, because of the numerous interim analyses, the $\mathrm{p}$-value should have been 0.0021 [63]. Thus, the difference was not statistically significant. The corresponding Kaplan-Meier graph is shown in > Fig. 2. Interestingly enough, the analysis regarding PCR was also repeated. While 602 patients participated in the initial analysis (pCR difference $13.6 \%$ ), now all 1174 patients in the intention-to-treat population participated. The $\mathrm{PCR}$ rate in the chemotherapy arm was $55.6 \%$ and in the pembrolizumab + chemotherapy arm $63.0 \%$. So the difference was only $7.5 \%$ [63].

\section{Quality of life under neoadjuvant therapy with immune checkpoint inhibitors}

With the KEYNOTE-522 trial, the NeoTRIP trial and the IMpassion031 trial, three larger prospective randomised trials involving patients with TNBC and neoadjuvant chemotherapy have been published [64-66]. Two trials revealed an increase in PCR irrespective of PD-L1 expression (KEYNOTE-522: 51.2\% $\rightarrow 64.8 \%$ (in 


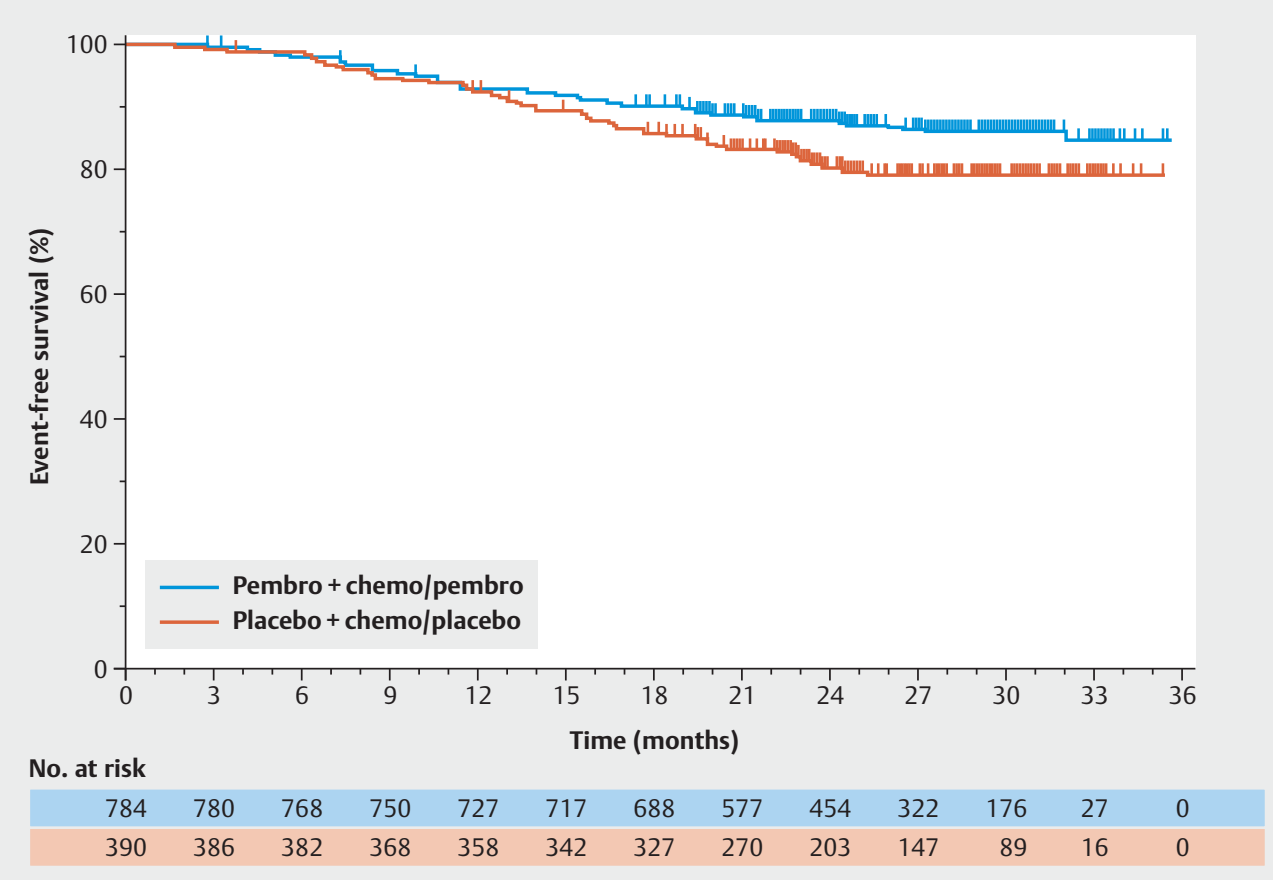

- Fig. 2 Kaplan-Meier estimator for event-free survival in the KEYNOTE-522 trial at the third interim analysis (from [63]).

initial analysis); IMpassion031 $41.1 \% \rightarrow 57.6 \%)$. Since the sample comprised patients with excellent chances of being cured in case of $\mathrm{PCR}$ and because the possible, if any, survival benefit arising from the approx. $15 \%$ improvement in the $\mathrm{PCR}$ rate is still unclear, the side effects of the additional immune checkpoint inhibition are of particular interest. $>$ Table 2 lists the incidence of side effects typically associated with immune checkpoint inhibitors. This data has now been supplemented by Patient Reported Outcomes (PRO, quality of life assessment) from the IMpassion031 trial [67]. This is true for both the neoadjuvant and adjuvant phases of the trial (patients in the atezolizumab arm received neoadjuvant atezolizumab in addition to chemotherapy and 11 adjuvant atezolizumab cycles every 3weeks) [64]. Figs. 3 and 4 present the changes from baseline for the EORTC-QLQC30 HrQoL (Health-related Quality of Life) total score and the fatigue subscale. It was found that the chemotherapy dosing interval affected the quality of life in both randomisation arms. In both randomisation arms, scores recovered after surgery, but there is the impression that patients in the atezolizumab arm had worse scores than patients in the arm without checkpoint inhibition. However, the authors emphasised that the analyses were purely descriptive and that the confidence intervals overlapped. They concluded that quality of life was similar in both randomisation arms [67]. Nevertheless, it must be noted that the numerical trend was consistent over the entire observation period and no statistical comparison was carried out. There is also no long-term follow-up data for long-term side effects.
- Table 2 Adverse events of special interest (AESI) in the IMpassion031, NeoTRIP and KEYNOTE-522 trials [64-66]. The illustration is not intended to imply any comparison. The trial populations were quite different, e.g., with more patients without ECOG 0 in the KEYNOTE-522 trial.

\begin{tabular}{|c|c|c|c|}
\hline & KEYNOTE-355 & NeoTRIP & IMpassion031 \\
\hline \multirow{2}{*}{$\begin{array}{l}\text { No. of patients } \\
\text { treated with } \\
\text { PD-L1/PD-1 } \\
\text { inhibitors }\end{array}$} & 781 & 138 & 164 \\
\hline & $\begin{array}{l}\text { \% occurrence } \\
\text { all grades }\end{array}$ & & $\begin{array}{l}\text { \% occurrence } \\
\text { all grades }\end{array}$ \\
\hline Infusion reaction & 16.9 & 8.0 & 10.4 \\
\hline Hypothyroidism & 13.7 & 5.8 & 6.7 \\
\hline Hyperthyroidism & 4.6 & 0.7 & 3.0 \\
\hline Adrenal failure & 2.3 & NR & 0 \\
\hline $\begin{array}{l}\text { Hypophysitis/ } \\
\text { encephalitis }\end{array}$ & 1.8 & NR & 0.6 \\
\hline Colitis & 1.7 & 1.5 & 0.6 \\
\hline Hepatitis & 1.4 & 0.7 & 1.2 \\
\hline Pneumonitis & 1.3 & NR & 1.2 \\
\hline
\end{tabular}




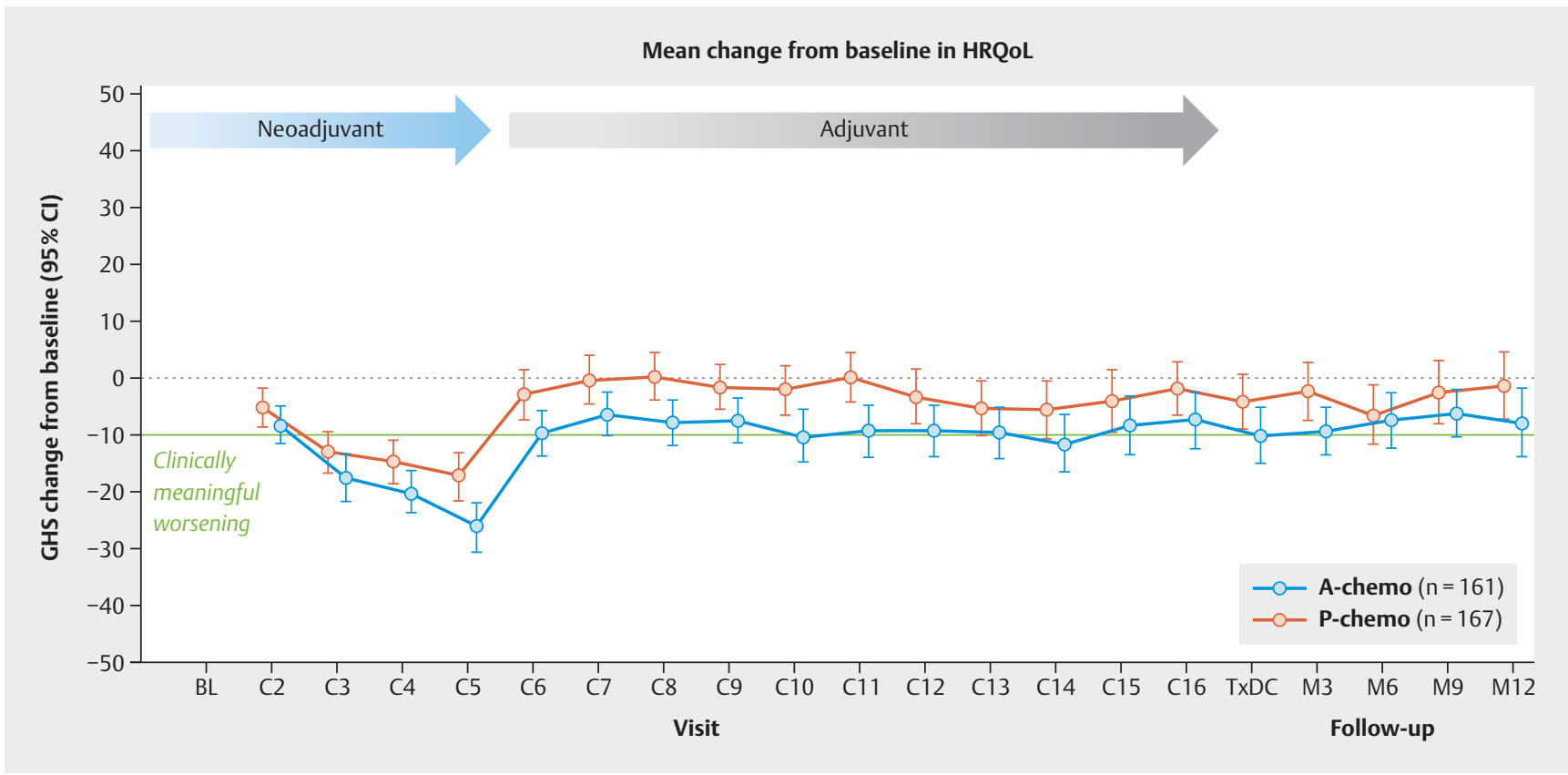

- Fig. 3 Change in health-related quality of life (EORTC-QLQC30) [67].

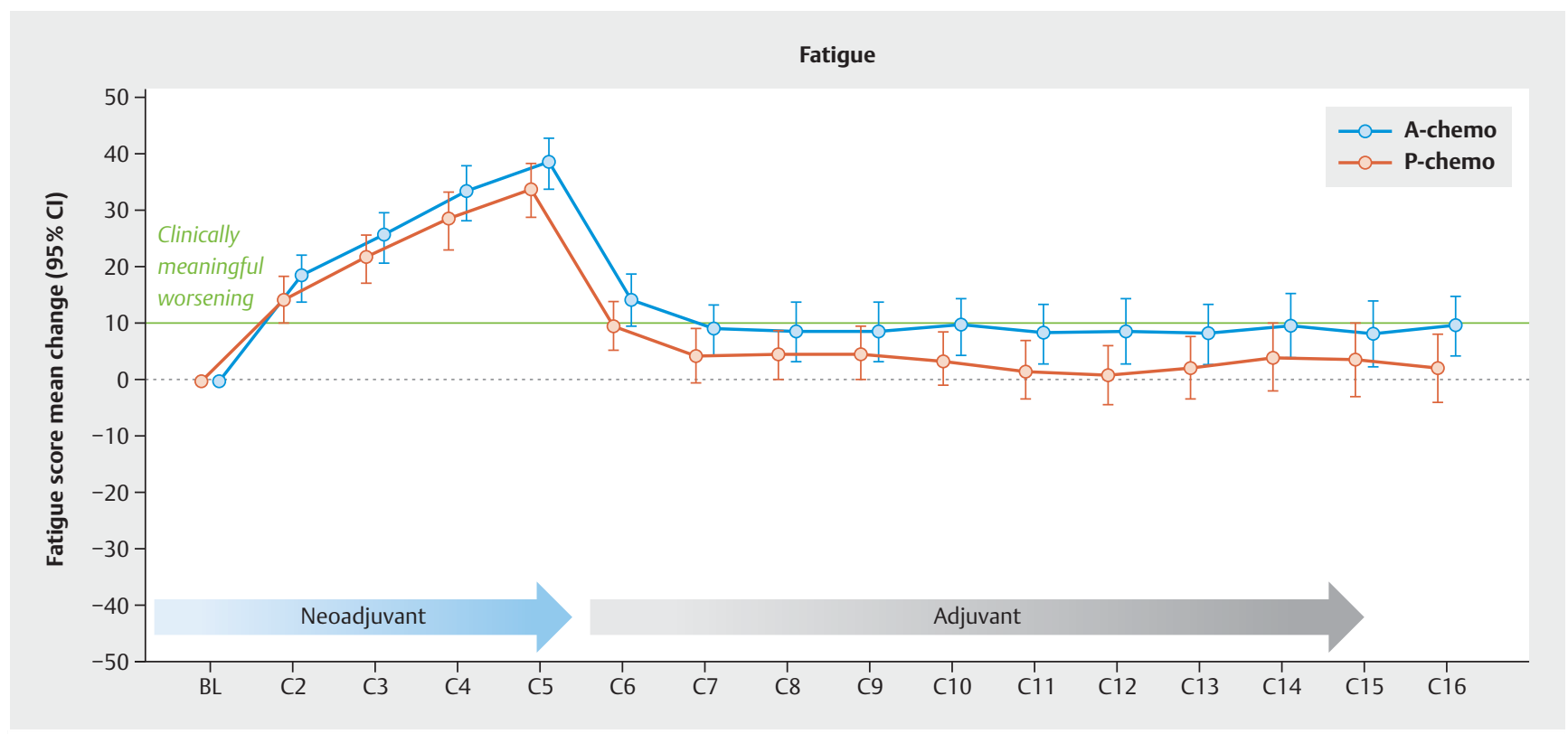

- Fig. 4 Change in fatigue subscore (EORTC-QLQC30) [67].

\section{Post-neoadjuvant Therapy}

\section{Prognostic models for patients after neoadjuvant chemotherapy}

Pathologic complete response is an excellent predictor of prognosis post neoadjuvant chemotherapy, especially in patients with TNBC or HER2+ breast cancer [53-57]. However, for patients without $p C R$ and even for a few patients with $P C R$, there could be significant differences in prognosis. A number of papers have addressed this issue. The simplest approach is to follow the AJCC (American Joint Committee on Cancer) staging criteria, which can be used to classify patients into different prognostic groups after neoadjuvant chemotherapy [68].

These predictions can be improved by two additional models:

The CPS-EG score was developed precisely for this purpose [69, 70] and was also used in the PENELOPE-B trial as a predictive parameter for prognosis [71]. Later, the CPS-EG score was refined in- 
to the Neo-Bioscore [72]. CPS-EG and Neo-Bioscore assign certain tumour characteristics before and after chemotherapy to arbitrary points, which are summed up to a total (score). These different scores may result in better prognostic prediction than the AJCC criteria alone [69-72]. The continuously calculated residual cancer burden (RCB) represents another tool for predicting patient prognosis following neoadjuvant chemotherapy [73]. Residual tumour diameter, percentage of residual cancer cells, percentage of in situ tumour parts, number of affected lymph nodes, and the largest diameter of an affected lymph node together are all entered into a regression model to calculate the RCB, which is then categorised into 4 RCB classes: RCB-0 (corresponding to ypT0 ypN0), RCB-I: (minimal residual tumour, corresponding to cases below the 40th percentile of the regression model), RCB-II (moderate residual tumour, corresponding to cases between the 40th to 87th percentiles of the regression model) and RCB-III (extensive residual tumour, corresponding to cases above the 87 th percentile of the regression model) [73].

Another classification used in Germany is the regression grade according to Sinn $[74,75]$, where the categories of complete remission and invasive complete remission are combined with histopathologic criteria to classify the regression even further.

- Table $\mathbf{3}$ is a summary of the different classification systems.

Recently, a large trial comparing AJCC, RCB and the Neo-Bioscore was published [76]. This study enrolled 5328 patients undergoing neoadjuvant treatment by an international consortium. It was possible to apply the various classifications for residual cancer to 3730 of these patients. Both the Neo-Bioscore and the RCB classification categorised patients into prognostic groups that were better predictors of prognosis than AJCC staging alone [76]. Since the Neo-Bioscore also takes into account criteria prior to chemotherapy, it is possible to test whether this score has a prognostic potential within the subgroup of patients with pCR. In the analysis presented, this aspect could not be confirmed [76]. For the question in which AJCC stages the two scores can help to better predict prognosis, it was shown that the RCB score had its strength in patients with stage II TNBC and in HR+/HER2- patients with stage I breast cancer. The Neo-Bioscore, on the other hand, had additional prognostic value primarily in patients with stage I and III TNBC, in HR+/HER2- breast cancer and in stages II/II [76]. These analyses revealed that additional criteria can classify the prognosis following pCR much differently. Future studies should take this into account. Also, the integration of molecular markers such as the presence and amount of circulating tumour DNA [77] could provide additional information on how patients could be further treated in the absence of pCR post neoadjuvant chemotherapy.

\section{Palbociclib in patients without $\mathrm{pCR}$ after neoadjuvant chemotherapy and high risk of relapse}

The PENELOPE-B trial, a collaboration of the GBG (German Breast Group), the AGO-B (Arbeitsgemeinschaft Gynäkologische Onkologie-Brust), the NSABP (National Surgical Adjuvant Breast and Bowel Project) and the BIG (Breast International Group), studied whether adding palbociclib to standard anti-hormone therapy improves invasive relapse-free survival in patients with $\mathrm{HR}+/ \mathrm{HER} 2-$ tumour without PCR [71]. This required a CPS-EG status of either $\geq 3$ or 2
- Table 3 Different assessment methodologies of residual tumour burden regarding prognosis after neoadjuvant chemotherapy.

\begin{tabular}{|l|l|l|l|}
\hline Characteristic & \multicolumn{2}{|c|}{ Assessment methodology } \\
\hline $\begin{array}{l}\text { AJCC stage } \\
\text { post chemo- } \\
\text { therapy }\end{array}$ & $\begin{array}{l}\text { Residual } \\
\text { Cancer } \\
\text { Burden }\end{array}$ & $\begin{array}{l}\text { Neo-Bioscore } \\
\text { (formerly } \\
\text { CPS-EG) }\end{array}$ \\
\hline $\begin{array}{l}\text { Tumour size } \\
\text { prior to nCTX }\end{array}$ & & + \\
\hline $\begin{array}{l}\text { Nodal status } \\
\text { prior to nCTX }\end{array}$ & & \\
\hline $\begin{array}{l}\text { Molecular } \\
\text { subtype prior } \\
\text { to nCTX }\end{array}$ & & + \\
\hline $\begin{array}{l}\text { Tumour grade } \\
\text { prior to nCTX }\end{array}$ & & + \\
\hline $\begin{array}{l}\text { Tumour size } \\
\text { post nCTX }\end{array}$ & + & + \\
\hline $\begin{array}{l}\text { Tumour cellular- } \\
\text { ity post nCTX }\end{array}$ & & + \\
\hline $\begin{array}{l}\text { No. of affected } \\
\text { LN post nCTX }\end{array}$ & + & + \\
\hline $\begin{array}{l}\text { Size largest LN } \\
\text { post nCTX } \\
\text { AJCC: American Joint Committee on Cancer; nCTX: neoadjuvant chemo- } \\
\text { therapy }\end{array}$ & & + \\
\hline
\end{tabular}

with positive lymph node status at the time of surgery. Patients were treated for 13 cycles (12 months) either by palbociclib in combination with endocrine therapy or by endocrine therapy alone and placebo. In the palbociclib arm, $80.5 \%$ of patients completed the 13 cycles of therapy, compared to $84.5 \%$ in the placebo arm. Thus, patient compliance under trial conditions was very good. With a mean age of 49 years, the patients were rather young and most of them had a CPS-EG score of $\geq 3$ (59.4\%). The primary endpoint of the trial was not met. With a median followup of 42.8 months, the hazard ratio was 0.93 (95\% Cl: 0.74-1.17; $\mathrm{p}=0.525)$ in favour of the palbociclib arm. The interim analysis for overall survival also revealed no significant difference for the combination with palbociclib $(\mathrm{HR}=0.87 ; 95 \% \mathrm{Cl}$ : 0.61-1.22; $\mathrm{p}=0.420)$.

Possible reasons for not meeting the primary endpoint may be whether the treatment was too short, whether palbociclib differs significantly from abemaciclib, even after the negative PALLAS trial, and whether risk group selection differed too much. The PENELOPE-B trial is the trial with the longest follow-up, so it remains to be seen whether in trials like the MonarchE trial with its longer follow-up the benefit in favour of the CDK4/6 inhibitor will persist. Since the PALLAS and MonarchE trials treated several thousand patients who had received neoadjuvant chemotherapy, we expect important insight from the $\mathrm{pCR}$, non-pCR and high versus low Ki67 subgroups and the study of intrinsic subtypes in the residual invasive tumour component. 


\section{Neratinib following (neo-)adjuvant therapy of HER2-positive breast cancer}

Neratinib, an oral tyrosine kinase inhibitor, binds to the intracellular domain of the EGF (epidermal growth factor) receptors HER1, HER2 and HER4. In the ExteNET trial, 2840 patients with HER2+ breast cancer following (neo-)adjuvant treatment with trastuzumab were treated for one year in the experimental arm with neratinib $(240 \mathrm{mg} /$ day) or in the other arm with placebo. The iDFS (invasive disease free survival) was significantly improved by this extended HER2-targeted treatment $[78,79]$. Since neratinib proved to be particularly effective in hormone receptor positive $(\mathrm{HR}+)$ cancers and when therapy was initiated within one year following trastuzumab ( $\mathrm{HR}+$ population/treatment initiated $\leq 1$ year), approval in the US and Europe was granted with the corresponding restrictions. Further subgroup analyses after 8 years of follow-up were presented at the SABCS in December 2020 and recently published [80]. In the HR+/therapy start $\leq 1$ year population, the 5 -year iDFS rate was 90.8 vs. $85.7 \%$ in the neratinib arm (delta $5.1 \%, \mathrm{HR}=0.58 ; 95 \% \mathrm{Cl}: 0.41-0.82$ ). In this subgroup, the estimated 8-year survival was also slightly more favourable with neratinib (91.5\%) than in the control arm (89.4\%). In the exploratory analysis of cases with residual tumour after neoadjuvant therapy (non-pCR), iDFS at 5 years with neratinib was $85.0 \%$ versus $77.6 \%$. Moreover, fewer brain metastases were observed in the neratinib group. The reported data suggest a consistent effect of neratinib even after a longer follow-up of 8 years. Since the ExteNET trial was conducted before the HER2 blockade with trastuzumab and pertuzumab or T-DM1 (trastuzumab emtansine) was approved, extrapolation of this data to current practice is limited. After completion of their trastuzumab therapy, affected patients should be informed about the option of neratinib treatment, especially if there is an increased risk of recurrence (e.g. non-pCR), and, if necessary, instructed in the prevention and management of frequent diarrhoea.

\section{Adjuvant Treatment of Breast Cancer Patients}

\section{CDK4/6 inhibitors in adjuvant therapy}

In adjuvant therapy, several trials have studied the addition of a CDK4/6 inhibitor to endocrine treatment. The adjuvant trial with abemaciclib (MonarchE) has already been reported after an interim analysis [81]. Now the final analysis after 390 events in terms of invasive relapse-free survival has been presented [82]. This had a longer median follow-up time of 19.1 months than the interim analysis (15.5 months) and 67 additional events. A total of 5637 patients were randomised into two arms, either to endocrine treatment and placebo or to endocrine treatment and abemaciclib for 2 years. Various criteria for a high-risk population with an increased risk of recurrence had to be fulfilled [81]. At the time of analysis, more than 1400 patients had completed treatment, while almost 3300 patients were still on it [82]. The hazard ratio $(\mathrm{HR}=0.713 ; 95 \% \mathrm{Cl}: 0.583-0.871)$ resembled that of the interim analysis ( $\mathrm{HR}=0.747 ; 95 \% \mathrm{Cl}: 0.598-0.932)$ [82]. In addition to this principal analysis, data was also presented relating to the subgroup of patients with $\mathrm{Ki}-67 \geq 20 \%$ and other clinically unfavourable prognostic factors [83]. In this group with a very high risk of relapse, the hazard ratio was 0.643 (95\% Cl: $0.475-0.872)$, with a similar effect in the group with a high clinical risk of relapse and $\mathrm{Ki}$ 67 below 20\% (HR=0.685; 95\% Cl: 0.462-1.017) [83].

\section{Adjuvant chemotherapy in patients with hormone receptor-positive tumours}

The TailorX trial established a data set for patients with early, node-negative, HR+ and HER2- breast cancer in which the subgroup of patients with excellent prognosis as determined by OncotypeDX demonstrated a benefit from additive adjuvant chemotherapy compared to endocrine therapy alone. In this trial, postmenopausal patients with a recurrence score of 11-25 were shown not to benefit from chemo- and endocrine therapy compared to endocrine therapy alone [84]. Initially, the clinical criterion tumour size and the pathohistologic criteria grading and Ki 67 were not evaluated in this analysis.

The RxPONDER trial (SWOG1007) recently presented was a similar trial, but with a node-positive (1-3 positive lymph nodes) population [85]. Similar to the TailorX trial, patients with early $\mathrm{HR}+$ /HER2 - breast cancer with a recurrence score of $\leq 25$ were randomised into a chemo-endocrine arm and an arm in which only standard anti-hormone therapy was administered. Patients with a recurrence score above 25 received chemotherapy followed by anti-hormone therapy. One of the most important issues in recent years has been whether the Recurrence Score would have an independent predictive effect in predicting the benefit of chemotherapy versus endocrine therapy alone. Therefore, the primary endpoint of the trial was the correlation between the continuous recurrence score and the randomisation arm. It was tested whether the difference between the randomisation arms would increase the higher the recurrence score was. If this primary analysis was negative, another primary analysis would study whether the recurrence score and the randomisation arm were independent prognostic factors in patients with a recurrence score of $0-25$. This design is important when interpreting the trial.

The RxPONDER trial was evaluated with 5083 randomised patients and 410 events. Most patients were postmenopausal (66.8\%), had one positive lymph node (65.5\%) and a recurrence score of $14-25$ (57.2\%).

The primary analysis was negative (HR for the interaction variable: 1.02 [95\% Cl: 0.98-1.06; $\mathrm{p}=0.30]$ ]) Thus, it can be concluded that in the RxPONDER trial, the recurrence score had no predictive value for the efficacy of chemotherapy followed by endocrine therapy compared to endocrine therapy alone. When analysing whether the respective randomisation arm and the recurrence score would predict patient prognosis, it was shown that both chemotherapy (compared to endocrine therapy) and the recurrence score had an independent prognostic effect. Chemotherapy resulted in a risk reduction for invasive relapse-free survival with a hazard ratio of $0.81(95 \% \mathrm{Cl}: 0.67-0.96)$ and the recurrence score showed a hazard ratio of 1.06 (95\% Cl: 1.07-1.07) per incremental unit. In a further analysis, the benefit for the chemotherapy arm could be attributed almost entirely to the group of premenopausal patients. In this group, the hazard ratio favouring chemotherapy was 0.54 (95\% Cl: 0.38-0.76, $\mathrm{p}=0.0004)$ and in the postmenopausal group $0.97(95 \% \mathrm{Cl}: 0.78-1.22 ; \mathrm{p}=0.82)$. 


\section{Self registration}

\section{Trial information}

www.corona-register.de queries, information leaflets/flyers for surgeries, departments, hospitals

Trial information for patients and redirection to self-registration for trial

\section{Registration - PWA}

https:/|therapie.freeda.one Patient self-registration with the Progressive Web App (PWA) freeda.one

\section{Representative}

Patients add someone they trust, who registers via https://partner.freeda.one

Questionnaires until end of observation

\section{Trial roadmap}

Cancer patient ( $\mathrm{P})$ :

$\geq 18$ years, informed consent, approx. $10 \%$ with COVID-19

Representative (V):

$\geq 18$ years, informed consent
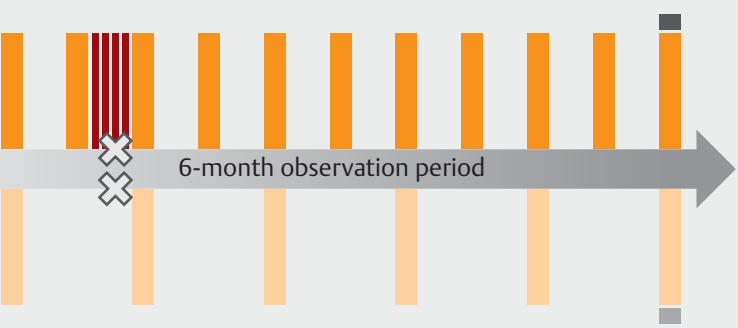

P-baseline ( $1 \times$ at beginning)

Disease, treatment, possible

SARS-CoV-2 history

P-regular (biweekly)

Course/change/pause of

treatment, $\mathrm{mood} / \mathrm{care}$

issues, infection monitoring

V-baseline $(1 \times$ at beginning $)$ Burden corona situation

V-regular (every 4 weeks)

Burden corona situation;

serious medical course

patient

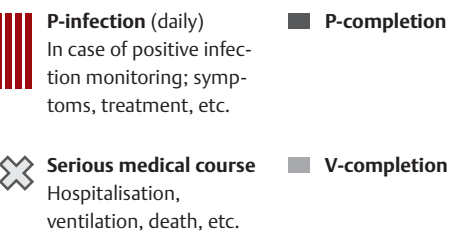

- Fig. 5 DEfenseCOVID-19 - Registration process and study workflow.

In the premenopausal group, the difference also translated into better overall survival under chemotherapy with a hazard ratio of 0.47 (95\% Cl: 0.24-0.94; $\mathrm{p}=0.032$ ).

It is not known whether the effect of chemotherapy is due to the cytotoxicity or to an anti-hormonal effect by reducing ovarian function. It is also questionable whether a multigene assay is necessary at all in nodal-positive, premenopausal patients in order to make a decision for or against chemotherapy, since even the patients with only one affected lymph node and a very low score of $0-13$ still benefited significantly from chemotherapy by $5 \%$ in absolute terms. A similar issue arose in postmenopausal patients, as the groups with a Recurrence Score of 0-13 and of 14-25 did not differ. Unfortunately, the study design specified chemotherapy for all patients with a recurrence score above 25 , but it is certainly questionable whether a cut-off of 25 here identifies the group of HR+/HER2- high-risk patients who will benefit from chemotherapy. Also missing from this evaluation was information on tumour size, grading and Ki-67.

\section{Breast Cancer During the COVID-19 Pandemic}

In the COVID-19 pandemic triggered by the Severe Acute-Respiratory Syndrome Coronavirus type-2 (SARS-CoV-2), cancer patients constitute a special risk group, with the pandemic having implications in all areas of care and treatment of, e.g., breast cancer. Between March and April 2020, 23.8\% fewer breast cancer cases were treated in German hospitals compared to the same period the previous year. It is possible that the pandemic has resulted in reduced oncological care, because cancer surgery had to be postponed or even cancelled altogether [86]. The professional societies DGHO
(German Society of Haematology and Medical Oncology), ESMO, ASCO, and others have developed guidelines and recommendations for the management and prioritisation of treatment interventions in breast cancer during the COVID pandemic [87-91].

According to the known current evidence, mortality rates for cancer patients with concomitant COVID-19 are significantly higher than in the general COVID-19 population, and are associated with increased age, male gender and prior conditions [92, 93]. The mortality rates published so far vary widely [94-96]. Currently, mortality rates of cancer patients with COVID-19 are much higher at 25-30\% [92, 93]. A meta-analysis of cohort studies of mortality in patients hospitalised for cancer and COVID-19 found a pooled 30-day mortality rate of $30 \%$ (95\% Cl: $25-35 \%$ ), with a rate of $26 \%$ (95\% Cl: $22-31 \%$ ) for the subgroup with solid tumours [93]. However, it should be noted that meta-analysis included mostly inpatient cases and that the cohorts came from different health care systems. For studies with a higher mean age, it was shown that there is a correlation between higher mortality rate and higher percentage of patients undergoing concurrent cancer treatment. But this could not be demonstrated for studies with a lower mean age [93]. In general, initial analyses of the COVID-19 and Cancer Consortium (CCC-19) registry demonstrated that cancer patients had an increased standardised incidence ratio (SIR) of mortality with chemotherapy (1.31 [1.00-1.69]) and a decreased SIR with endocrine therapy $(0.62[0.42-0.88])<2$ weeks prior to COVID-19 onset. Targeted therapy 2-3 months prior to COVID-19 onset has also been reported to date to have a higher SIR (2.15 [1.14-3.68]). Decisive data on breast cancer treatment is still pending. Furthermore, little is known about subgroups of cancer patients and their potential impact on mortality associated 
with COVID-19. It can also be assumed that patients with a cancer long in the past have risk profiles different from those patients who contracted SARS-CoV-2 infection while undergoing cancer treatment. Some cancer therapies, such as checkpoint inhibitors, markedly modulate the immune system; for this reason, it is necessary to closely monitor the course of SARS-CoV-2 infections in these patients [97]. Further insight into possible correlations between SARS-CoV-2 infection and cancer treatment is expected from the DEfenseCOVID-19 trial (www.corona-register.de).

The nationwide German self-registration trial DEfenseCOVID19 aims to show whether certain cancer treatments pose a risk during SARS-CoV-2 infection. For this purpose, cancer patients who optionally have or have had a SARS-CoV-2 infection are enrolled in the trial and monitored for 6 months. Among other things, patients will answer specific questions about their cancer, course of treatment, prior conditions and possible SARS-CoV-2 infection ( $\triangleright$ Fig. 5). Serious medical events (including death) are also documented by a trusted third party designated by the cancer patient. In addition, data on the mental state of cancer patients during the pandemic is collected and published at regular intervals on the website www.corona-thermometer.de to provide updates on the ongoing trial. The strength of the trial is being able to include all COVID-19 cases in the trial, not just the serious courses. The data collected will be analysed in terms of morbidity and mortality following SARS-CoV-2 infection. By recognising particular risks, treatment decisions could be reconsidered and a riskbenefit analysis performed, taking into account any existing risk of infection. Recruitment started in Q4/2020 and is expected to continue until Q4/2021. Cancer patients are informed about the trial via the website www.corona-register.de and will continue to be informed about the trial and data protection aspects during the registration process before consenting to the trial.

\section{Acknowledgements}

This paper was produced in part as a result of funding from the following companies: onkowissen.de; Hexal; Pfizer; Lilly; and Novartis; as well as the PRAEGNANT network, which is supported by Pfizer; Hexal; MSD; Daiichi-Sankyo; Merrimack; Eisai; AstraZeneca; and Novartis. No company had any part in the preparation and recommendations of this manuscript. Sole responsibility for the content of the manuscript rests with the authors.

\section{Conflict of Interest}

E. S. received honoraria from Roche, Celgene, AstraZeneca, Novartis, Pfizer, Tesaro, Aurikamed GmbH, MCI Deutschland GmbH, bsh medical communications $\mathrm{GmbH}$, Onkowissen TV.

B. A. received honoraria from AstraZeneca, Genomic Health, Roche, Novartis, Celgene, Lilly, MSD, Eisai, Teva, Tesaro, Daiichi-Sankyo and Pfizer.

E. B. received honoraria from Novartis, Hexal, BMS, Lilly, Pfizer, Roche, MSD, Bayer, Ipsen, Bluebird, BBraun and onkowissen.de for consulting, clinical research management or medical education activities.

N.D. has received honoraria from MSD, Roche, AstraZeneca, Teva, Mentor and MCI Healthcare.

P. A. F. received honoraria from Novartis, Pfizer, Roche, Amgen, Celgene, Daiichi-Sankyo, onkowissen.de, AstraZeneca, Merck-Sharp \& Dohme, Eisai, Puma and Teva. His institution conducts research with funding from Novartis and Biontech.
T. N. F. has participated on advisory boards for Amgen, Daiichi Sankyo, Novartis, Pfizer, and Roche and has received honoraria for lectures from Amgen, Celgene, Daiichi Sankyo, Roche, Novartis and Pfizer.

A.D.H. received speaker and consultancy honoraria from AstraZeneca, Genomic Health, Roche, Novartis, Celgene, Lilly, MSD, Eisai, Teva, Tesaro, Daiichi-Sankyo, Hexal and Pfizer.

C. J. reports personal fees from AstraZeneca, Exact Sciences, Lilly, Novartis and Roche during the conduct of the study.

W. J. has received research Grants and/or honoraria from Sanofi-Aventis, Daiichi-Sankyo, Novartis, Roche, Pfizer, Lilly, AstraZeneca, Chugai, GSK, Eisai, Cellgene and Johnson\&Johnson.

C. K.-L. has received honoraria from Roche, AstraZeneca, Celgene, Novartis, Pfizer, Lilly, Hexal, Amgen, Eisai, and SonoScape, honoraria for consultancy from Phaon Scientific, Novartis, Pfizer, and Celgene, research funding from Roche, Novartis, and Pfizer, and travel grants from Novartis and Roche.

H.-C. K. has received honoraria from Pfizer, Novartis, Roche, Genomic Health/Exact Sciences, Amgen, AstraZeneca, Riemser, Carl Zeiss Meditec, Teva, Theraclion, Janssen-Cilag, GSK, LIV Pharma, Lily, SurgVision, Onkowissen and MSD, travel support from Carl Zeiss Meditec, LIV Pharma, Novartis, Amgen, Pfizer, Daiichi Sankyo, Tesaro and owns stock of Theraclion SA and Phaon Scientific GmbH.

D. L. received honoraria from Amgen, AstraZeneca, Celgene, Lilly, Loreal, MSD, Novartis, Pfizer, Tesaro, Teva.

M.P.L. has participated on advisory boards for AstraZeneca, Lilly, MSD, Novartis, Pfizer, Eisai, Exact Sciences and Roche and has received honoraria for lectures from MSD, Lilly, Roche, Novartis, Pfizer, Exact Sciences, AstraZeneca, medac and Eisai.

V. M. received speaker honoraria from Amgen, Astra Zeneca, DaiichiSankyo, Eisai, Pfizer, MSD, Novartis, Roche, Teva, Seattle Genetics and consultancy honoraria from Genomic Health, Hexal, Roche, Pierre Fabre, Amgen, ClinSol, Novartis, MSD, Daiichi-Sankyo, Eisai, Lilly, Tesaro, Seattle Genetics and Nektar. Institutional research support from Novartis, Roche, Seattle Genetics, Genentech. Travel grants: Roche, Pfizer, Daiichi Sankyo.

M.S. has previously received honoraria for advisory board duty from Roche, Pfizer, Novartis, Astra-Zeneca and Eisai.

A.S. received honoraria from Roche, Celgene, AstraZeneca, Novartis, Pfizer, Zuckschwerdt Verlag $\mathrm{GmbH}$, Georg Thieme Verlag, Aurikamed $\mathrm{GmbH}, \mathrm{MCl}$ Deutschland $\mathrm{GmbH}$, bsh medical communications $\mathrm{GmbH}$ and promedicis $\mathrm{GmbH}$.

F. S. participated on advisory boards for Novartis, Lilly, Amgen and Roche and received honoraria for lectures from Roche, AstraZeneca, MSD, Novartis and Pfizer.

H. T. received honoraria from Novartis, Roche, Celgene, Teva, Pfizer, Astra Zeneca and travel support from Roche, Celgene and Pfizer. C. T. Advisory boards, lectures: Amgen, AstraZeneca, Celgen, DaiichiSankyo, Eisai, Lilly, MSD, Mundipharma, Medapharm, Novartis, Pfizer, Pierre-Fabre, Roche, Tesaro, and Vifor.

C.U. received honoraria from Roche, Novartis, Pfizer, Astra-Zeneca, MSD and onkowissen.de.

M.U. all honoraria went to the institution/employer: Abbvie, Amgen, Astra Zeneca, Celgene, Daichi Sankyo, Eisai, Lilly, MSD Merck, Mundipharma, Myriad Genetics, Pfizer, PUMA Biotechnology, Roche, Sanofi Aventis, Novartis, Pierre Fabre.

M. W. has participated on advisory boards for AstraZeneca, Lilly, MSD, Novartis, Pfizer and Roche.

A.W. participated on advisory boards for Novartis, Lilly, Amgen, Pfizer, Roche, Tesaro, Eisai and received honoraria for lectures from Novartis, Pfizer, Aurikamed, Roche, Celgene.

R.W. has received personal fees/travel support from Agendia, Amgen, Aristo, Astra Zeneca, Boehringer Ingelheim, Carl Zeiss, Celgene, Clinsol, Daiichi-Sankyo, Eisai, Exact Sciences, Genomic Health, Glaxo Smith Kline, Hexal, Lilly, Medstrom Medical, MSD, Mundipharma, Nanostring, Novartis, Odonate, Paxman, Palleos, Pfizer, Pierre Fabre, Puma Biotechnology, Riemser, Roche, Sandoz/Hexal, Seattle Genetics, Tesaro Bio, Teva, Veracyte and Viatris. 
M. T. has participated on advisory boards for AstraZeneca, ClearCut, Clovis, Daiichi Sankyo, Eisai, Exact Sciences, GSK, Lilly, MSD, Neodynamics, Novartis, Pfizer, pfm medical, Pierre-Fabre, Roche and Sysmex and has received honoraria for lectures from Amgen, AstraZeneca, Clovis, Daiichi Sankyo, Eisai, Hexal, GSK, Lilly, MSD, Roche, Novartis, Pfizer, Exact Sciences and pfm medical and has received trial funding by Exact Sciences and Endomag.

The other authors have no conflict of interest to declare for this specific work.

\section{References}

[1] Ditsch N, Untch M, Kolberg-Liedtke C et al. AGO Recommendations for the Diagnosis and Treatment of Patients with Locally Advanced and Metastatic Breast Cancer: Update 2020. Breast Care (Basel) 2020; 15: 294-309

[2] Ditsch N, Untch M, Thill M et al. AGO Recommendations for the Diagnosis and Treatment of Patients with Early Breast Cancer: Update 2019. Breast Care (Basel) 2019; 14: 224-245

[3] Huober J, Schneeweiss A, Hartkopf AD et al. Update Breast Cancer 2020 Part 3 - Early Breast Cancer. Geburtshilfe Frauenheilkd 2020; 80: 11051114

[4] Lüftner D, Schneeweiss A, Hartkopf AD et al. Update Breast Cancer 2020 Part 2 - Advanced Breast Cancer: New Treatments and Implementation of Therapies with Companion Diagnostics. Geburtshilfe Frauenheilkd 2020; 80: 391-398

[5] Schneeweiss A, Hartkopf AD, Müller V et al. Update Breast Cancer 2020 Part 1 - Early Breast Cancer: Consolidation of Knowledge About Known Therapies. Geburtshilfe Frauenheilkd 2020; 80: 277-287

[6] Tesch H, Müller V, Wöckel A et al. Update Breast Cancer 2020 Part 4 Advanced Breast Cancer. Geburtshilfe Frauenheilkd 2020; 80: 11151122

[7] Hartkopf AD, Müller V, Wöckel A et al. Update Breast Cancer 2019 Part 1 - Implementation of Study Results of Novel Study Designs in Clinical Practice in Patients with Early Breast Cancer. Geburtshilfe Frauenheilkd 2019; 79: 256-267

[8] Schütz F, Fasching PA, Welslau M et al. Update Breast Cancer 2019 Part 4 - Diagnostic and Therapeutic Challenges of New, Personalised Therapies for Patients with Early Breast Cancer. Geburtshilfe Frauenheilkd 2019; 79: 1079-1089

[9] Wunderle M, Olmes G, Nabieva $\mathrm{N}$ et al. Risk, Prediction and Prevention of Hereditary Breast Cancer - Large-Scale Genomic Studies in Times of Big and Smart Data. Geburtshilfe Frauenheilkd 2018; 78: 481-492

[10] Fachal L, Aschard H, Beesley J et al. Fine-mapping of 150 breast cancer risk regions identifies 191 likely target genes. Nat Genet 2020; 52: 5673

[11] Wu L, Shi W, Long J et al. A transcriptome-wide association study of 229,000 women identifies new candidate susceptibility genes for breast cancer. Nat Genet 2018; 50: 968-978

[12] Milne RL, Kuchenbaecker KB, Michailidou K et al. Identification of ten variants associated with risk of estrogen-receptor-negative breast cancer. Nat Genet 2017; 49: 1767-1778

[13] Michailidou K, Lindström S, Dennis J et al. Association analysis identifies 65 new breast cancer risk loci. Nature 2017; 551: 92-94

[14] Day FR, Thompson DJ, Helgason $\mathrm{H}$ et al. Genomic analyses identify hundreds of variants associated with age at menarche and support a role for puberty timing in cancer risk. Nat Genet 2017; 49: 834-841

[15] Michailidou K, Beesley J, Lindstrom S et al. Genome-wide association analysis of more than 120,000 individuals identifies 15 new susceptibility loci for breast cancer. Nat Genet 2015; 47: 373-380

[16] Day FR, Ruth KS, Thompson DJ et al. Large-scale genomic analyses link reproductive aging to hypothalamic signaling, breast cancer susceptibility and BRCA1-mediated DNA repair. Nat Genet 2015; 47: 1294-1303
[17] Pharoah PD, Tsai YY, Ramus S] et al. GWAS meta-analysis and replication identifies three new susceptibility loci for ovarian cancer. Nat Genet 2013; 45: 362-370, 370e1-370e2

[18] Michailidou K, Hall P, Gonzalez-Neira A et al. Large-scale genotyping identifies 41 new loci associated with breast cancer risk. Nat Genet 2013; 45: 353-361, 361e1-361e2

[19] Garcia-Closas M, Couch FJ, Lindstrom S et al. Genome-wide association studies identify four ER negative-specific breast cancer risk loci. Nat Genet 2013; 45: 392-398, 398e1-398e2

[20] Bojesen SE, Pooley KA, Johnatty SE et al. Multiple independent variants at the TERT locus are associated with telomere length and risks of breast and ovarian cancer. Nat Genet 2013; 45: 371-384, 384e1-384e2

[21] Ghoussaini M, Fletcher O, Michailidou K et al. Genome-wide association analysis identifies three new breast cancer susceptibility loci. Nat Genet 2012; 44: 312-318

[22] Haiman CA, Chen GK, Vachon CM et al. A common variant at the TERTCLPTM1 L locus is associated with estrogen receptor-negative breast cancer. Nat Genet 2011; 43: 1210-1214

[23] Antoniou AC, Wang X, Fredericksen ZS et al. A locus on 19p13 modifies risk of breast cancer in BRCA1 mutation carriers and is associated with hormone receptor-negative breast cancer in the general population. Nat Genet 2010; 42: 885-892

[24] Ghoussaini M, French JD, Michailidou K et al. Evidence that the 5p12 Variant rs10941679 Confers Susceptibility to Estrogen-Receptor-Positive Breast Cancer through FGF10 and MRPS30 Regulation. Am J Hum Genet 2016; 99: 903-911

[25] Couch F], Kuchenbaecker KB, Michailidou $\mathrm{K}$ et al. Identification of four novel susceptibility loci for oestrogen receptor negative breast cancer. Nat Commun 2016; 7: 11375

[26] Purrington KS, Slager S, Eccles D et al. Genome-wide association study identifies 25 known breast cancer susceptibility loci as risk factors for triple-negative breast cancer. Carcinogenesis 2014; 35: 1012-1019

[27] Stevens KN, Fredericksen Z, Vachon CM et al. 19p13.1 is a triple-negative-specific breast cancer susceptibility locus. Cancer Res 2012; 72: 1795-1803

[28] Kolberg HC, Schneeweiss A, Fehm TN et al. Update Breast Cancer 2019 Part 3 - Current Developments in Early Breast Cancer: Review and Critical Assessment by an International Expert Panel. Geburtshilfe Frauenheilkd 2019; 79: 470-482

[29] Shimelis H, LaDuca H, Hu C et al. Triple-Negative Breast Cancer Risk Genes Identified by Multigene Hereditary Cancer Panel Testing. J Natl Cancer Inst 2018; 110: 855-862

[30] Couch F], Shimelis H, Hu C et al. Associations Between Cancer Predisposition Testing Panel Genes and Breast Cancer. JAMA Oncol 2017; 3: 1190-1196

[31] Breast Cancer Association Consortium; Dorling L, Carvalho S, Allen J et al. Breast Cancer Risk Genes - Association Analysis in More than 113,000 Women. N Engl J Med 2021; 384: 428-439

[32] Hu C, Hart SN, Gnanaolivu R et al. A Population-Based Study of Genes Previously Implicated in Breast Cancer. N Engl J Med 2021; 384: 440-451

[33] Loibl S, Weber KE, Timms KM et al. Survival analysis of carboplatin added to an anthracycline/taxane-based neoadjuvant chemotherapy and HRD score as predictor of response - final results from GeparSixto. Ann Oncol 2018; 29: 2341-2347

[34] Fasching PA, Jackisch C, Rhiem K et al. GeparOLA: A randomized phase II trial to assess the efficacy of paclitaxel and olaparib in comparison to paclitaxel/carboplatin followed by epirubicin/cyclophosphamide as neoadjuvant chemotherapy in patients (pts) with HER2-negative early breast cancer (BC) and homologous recombination deficiency (HRD). J Clin Oncol 2019; 37 (15_suppl): 506 
[35] Fasching PA, Loibl S, Hu C et al. BRCA1/2 Mutations and Bevacizumab in the Neoadjuvant Treatment of Breast Cancer: Response and Prognosis Results in Patients With Triple-Negative Breast Cancer From the GeparQuinto Study. J Clin Oncol 2018; 36: 2281-2287

[36] Hahnen E, Lederer B, Hauke J et al. Germline Mutation Status, Pathological Complete Response, and Disease-Free Survival in Triple-Negative Breast Cancer: Secondary Analysis of the GeparSixto Randomized Clinical Trial. JAMA Oncol 2017; 3: 1378-1385

[37] Wunderle M, Gass P, Häberle L et al. BRCA mutations and their influence on pathological complete response and prognosis in a clinical cohort of neoadjuvantly treated breast cancer patients. Breast Cancer Res Treat 2018; 171: 85-94

[38] Litton JK, Scoggins ME, Hess KR et al. Neoadjuvant Talazoparib for Patients With Operable Breast Cancer With a Germline BRCA Pathogenic Variant. J Clin Oncol 2020; 38: 388-394

[39] Litton JK, Rugo HS, Ettl J et al. Talazoparib in Patients with Advanced Breast Cancer and a Germline BRCA Mutation. N Engl J Med 2018; 379 : 753-763

[40] Robson M, Im SA, Senkus E et al. Olaparib for Metastatic Breast Cancer in Patients with a Germline BRCA Mutation. N Engl J Med 2017; 377: $523-$ 533

[41] Turner NC, Telli ML, Rugo HS et al. A Phase II Study of Talazoparib after Platinum or Cytotoxic Nonplatinum Regimens in Patients with Advanced Breast Cancer and Germline BRCA1/2 Mutations (ABRAZO). Clin Cancer Res 2019; 25: 2717-2724

[42] Tung NM, Robson ME, Ventz S et al. TBCRC048: Phase II Study of Olaparib for Metastatic Breast Cancer and Mutations in Homologous Recombination-Related Genes. J Clin Oncol 2020; 38: 4274-4282

[43] lyengar NM, Arthur R, Manson JE et al. Association of Body Fat and Risk of Breast Cancer in Postmenopausal Women With Normal Body Mass Index: A Secondary Analysis of a Randomized Clinical Trial and Observational Study. JAMA Oncol 2019; 5: 155-163

[44] Premenopausal Breast Cancer Collaborative Group; Schoemaker M], Nichols HB, Wright LB et al. Association of Body Mass Index and Age With Subsequent Breast Cancer Risk in Premenopausal Women. JAMA Oncol 2018; 4: e181771

[45] Picon-Ruiz M, Morata-Tarifa C, Valle-Goffin J] et al. Obesity and adverse breast cancer risk and outcome: Mechanistic insights and strategies for intervention. CA Cancer J Clin 2017; 67: 378-397

[46] Torres-de la Roche LA, Steljes I, Janni W et al. The Association between Obesity and Premenopausal Breast Cancer According to Intrinsic Subtypes - a Systematic Review. Geburtshilfe Frauenheilkd 2020; 80: 601610

[47] Widschwendter P, Friedl TW, Schwentner L et al. The influence of obesity on survival in early, high-risk breast cancer: results from the randomized SUCCESS A trial. Breast Cancer Res 2015; 17: 129

[48] Debras, C, Chazelas E, Srour B et al. Glycemic index, glycemic load and breast cancer risk: Results from the prospective NutriNet-Santé cohort. San Antonio Breast Cancer Symposium 2020; 2020: GS2-07. Accessed March 16, 2021 at: https://www.abstractsonline.com/pp8/\#!/9223/presentation/583

[49] Gopalakrishnan V, Spencer CN, Nezi L et al. Gut microbiome modulates response to anti-PD-1 immunotherapy in melanoma patients. Science 2018; 359: 97-103

[50] Robinson T, Edmunds G, Hayes B et al. Exploring the causal role of the human gut microbiome in breast cancer risk using mendelian randomization. San Antonio Breast Cancer Symposium 2020; 2020: GS2-06. Accessed March 16, 2021 at: https://www.abstractsonline.com/pp8/ \#!/9223/presentation/582

[51] Zhang H, Ahearn TU, Lecarpentier ] et al. Genome-wide association study identifies 32 novel breast cancer susceptibility loci from overall and subtype-specific analyses. Nat Genet 2020; 52: 572-581
[52] Hughes DA, Bacigalupe R, Wang J et al. Genome-wide associations of human gut microbiome variation and implications for causal inference analyses. Nat Microbiol 2020; 5: 1079-1087

[53] Cortazar P, Zhang L, Untch M et al. Pathological complete response and long-term clinical benefit in breast cancer: the $\mathrm{CTNeoBC}$ pooled analysis. Lancet 2014; 384: 164-172

[54] Untch M, Fasching PA, Konecny GE et al. Pathologic complete response after neoadjuvant chemotherapy plus trastuzumab predicts favorable survival in human epidermal growth factor receptor 2-overexpressing breast cancer: results from the TECHNO trial of the AGO and GBG study groups. J Clin Oncol 2011; 29: 3351-3357

[55] Fasching PA, Heusinger K, Haeberle L et al. Ki67, chemotherapy response, and prognosis in breast cancer patients receiving neoadjuvant treatment. BMC Cancer 2011; 11: 486

[56] Huang M, O’Shaughnessy J, Zhao J et al. Evaluation of Pathologic Complete Response as a Surrogate for Long-Term Survival Outcomes in Triple-Negative Breast Cancer. J Natl Compr Canc Netw 2020; 18: 10961104

[57] Huang M, O'Shaughnessy J, Zhao J et al. Association of Pathologic Complete Response with Long-Term Survival Outcomes in Triple-Negative Breast Cancer: A Meta-Analysis. Cancer Res 2020; 80: 5427-5434

[58] Smith I, Robertson J, Kilburn L et al. Long-term outcome and prognostic value of Ki67 after perioperative endocrine therapy in postmenopausal women with hormone-sensitive early breast cancer (POETIC): an openlabel, multicentre, parallel-group, randomised, phase 3 trial. Lancet Oncol 2020; 21: 1443-1454

[59] Ma CX, Suman V, Leitchet AM et al. Neoadjuvant chemotherapy (NCT) response in postmenopausal women with clinical stage II or III estrogen receptor positive (ER+) and HER2 negative (HER2-) breast cancer (BC) resistant to endocrine therapy (ET) in the ALTERNATE trial (Alliance A011106). San Antonio Breast Cancer Symposium 2020; 2020: GS4-05. Accessed March 16, 2021 at: https://www.abstractsonline.com/pp8/ \#!/9223/presentation/683

[60] Kuemmel S, Gluz O, Nitz U et al. Neoadjuvant nab-paclitaxel weekly versus dose-dense paclitaxel followed by dose-dense EC in high risk HR +/HER2- early BC by: results from the neoadjuvant part of ADAPT HR +/HER2- trial. San Antonio Breast Cancer Symposium 2020; 2020: GS403. Accessed March 16, 2021 at: https://www.abstractsonline.com/pp8/ \#!/9223/presentation/681

[61] Untch M, Jackisch C, Schneeweiss A et al. NAB-Paclitaxel Improves Disease-Free Survival in Early Breast Cancer: GBG 69-GeparSepto. J Clin Oncol 2019; 37: 2226-2234

[62] Untch M, Jackisch C, Schneeweiss A et al. Nab-paclitaxel versus solventbased paclitaxel in neoadjuvant chemotherapy for early breast cancer (GeparSepto-GBG 69): a randomised, phase 3 trial. Lancet Oncol 2016; 17: 345-356

[63] Merck; FDA. Pembrolizumab: Combined FDA and Applicant ODAC Briefing Document for the Oncologic Drugs Advisory Committee (ODAC) Meeting on February 9, 2021. Accessed February 20, 2021 at: https:// www.fda.gov/media/145654/download

[64] Harbeck N, Zhang $\mathrm{H}$, Barrios $\mathrm{CH}$ et al. IMpassion031: Results from a phase III study of neoadjuvant (neoadj) atezolizumab + chemotherapy in early triple-negative breast cancer (TNBC). Ann Oncol 2020; 31 (suppl_4): S1142-S1215. doi:10.1016/annonc/annonc325

[65] Schmid P, Cortes J, Pusztai L et al. Pembrolizumab for Early Triple-Negative Breast Cancer. N Engl J Med 2020; 382: 810-821

[66] Gianni L, Huang C-S, Egle D et al. Pathologic complete response (pCR) to neoadjuvant treatment with or without atezolizumab in triple negative, early high-risk and locally advanced breast cancer. NeoTRIPaPDL1 Michelangelo randomized study. San Antonio Breast Cancer Symposium 2019; 2019: GS3-04. Accessed March 16, 2021 at: https://www. abstractsonline.com/pp8/\#!/7946/presentation/1911 
[67] Mittendorf, EA, Harbeck N, Zhang $\mathrm{H}$ et al. Patient-reported outcomes (PROs) from the Ph 3 IMpassion031 trial of neoadjuvant (NA) atezolizumab + chemo in early triple-negative breast cancer (eTNBC). San Antonio Breast Cancer Symposium 2020; 2020: GS3-02. Accessed March 16, 2021 at: https://www.abstractsonline.com/pp8/\#!/9223/presentation/ 1726

[68] Bergquist JR, Murphy BL, Storlie CB et al. Incorporation of Treatment Response, Tumor Grade and Receptor Status Improves Staging Quality in Breast Cancer Patients Treated with Neoadjuvant Chemotherapy. Ann Surg Oncol 2017; 24: 3510-3517

[69] Jeruss JS, Mittendorf EA, Tucker SL et al. Combined use of clinical and pathologic staging variables to define outcomes for breast cancer patients treated with neoadjuvant therapy. J Clin Oncol 2008; 26: 246-252

[70] Mittendorf EA, Jeruss JS, Tucker SL et al. Validation of a novel staging system for disease-specific survival in patients with breast cancer treated with neoadjuvant chemotherapy. J Clin Oncol 2011; 29: 1956-1962

[71] Loibl S, Marmé F, Martin M et al., Phase III study of palbociclib combined with endocrine therapy (ET) in patients with hormone-receptor-positive $(\mathrm{HR}+)$, HER2-negative primary breast cancerand with high relapse risk after neoadjuvant chemotherapy (NACT): First results from PENELOPE-B. San Antonio Breast Cancer Symposium 2020; 2020: GS1-02. Accessed March 16, 2021 at: https://www.abstractsonline.com/pp8/\#!/9223/presentation/666

[72] Mittendorf EA, Vila J, Tucker SL et al. The Neo-Bioscore Update for Staging Breast Cancer Treated With Neoadjuvant Chemotherapy: Incorporation of Prognostic Biologic Factors Into Staging After Treatment. JAMA Oncol 2016; 2: 929-936

[73] Symmans WF, Peintinger F, Hatzis $C$ et al. Measurement of residual breast cancer burden to predict survival after neoadjuvant chemotherapy. J Clin Oncol 2007; 25: 4414-4422

[74] Sinn HP, Schmid H, Junkermann $\mathrm{H}$ et al. Histological Regression of Breast-Cancer After Primary (Neoadjuvant) Chemotherapy. Geburtshilfe Frauenheilkd 1994; 54: 552-558

[75] von Minckwitz G, Untch M, Blohmer JU et al. Definition and impact of pathologic complete response on prognosis after neoadjuvant chemotherapy in various intrinsic breast cancer subtypes. J Clin Oncol 2012; 30: 1796-1804

[76] van der Noordaa MEM, Yau C, Shad S et al. Assessing prognosis after neoadjuvant therapy: A comparison between anatomic ypAJCC staging, Residual Cancer Burden Class and Neo-Bioscore. San Antonio Breast Cancer Symposium 2020; 2020: GS4-07. Accessed March 16, 2021 at: https://www.abstractsonline.com/pp8/\#!/9223/presentation/684

[77] McDonald BR, Contente-Cuomo T, Sammut SJ et al. Personalized circulating tumor DNA analysis to detect residual disease after neoadjuvant therapy in breast cancer. Sci Transl Med 2019; 11: eaax7392

[78] Chan A, Delaloge S, Holmes FA et al. Neratinib after trastuzumab-based adjuvant therapy in patients with HER2-positive breast cancer (ExteNET): a multicentre, randomised, double-blind, placebo-controlled, phase 3 trial. Lancet Oncol 2016; 17: 367-377

[79] Martin M, Holmes FA, Ejlertsen B et al. Neratinib after trastuzumabbased adjuvant therapy in HER2-positive breast cancer (ExteNET): 5-year analysis of a randomised, double-blind, placebo-controlled, phase 3 trial. Lancet Oncol 2017; 18: 1688-1700

[80] Chan A, Moy B, Mansi J et al. Final Efficacy Results of Neratinib in HER2positive Hormone Receptor-positive Early-stage Breast Cancer From the Phase III ExteNET Trial. Clin Breast Cancer 2021; 21: 80-91.e7

[81] Johnston SRD, Harbeck N, Hegg R et al. Abemaciclib Combined With Endocrine Therapy for the Adjuvant Treatment of HR+, HER2-, Node-Positive, High-Risk, Early Breast Cancer (monarchE). J Clin Oncol 2020; 38: 3987-3998
[82] O'Shaughnessy JA, Johnston S, Harbeck N et al. Primary outcome analysis of invasive disease-free survival for monarchE: abemaciclib combined with adjuvant endocrine therapy for high risk early breast cancer. San Antonio Breast Cancer Symposium 2020; 2020: GS1-01. Accessed March 16, 2021 at: https://www.abstractsonline.com/pp8/\#!/9223/ presentation/664

[83] Harbeck N, Johnston S, Fasching P et al. High Ki-67 as a biomarker for identifying patients with high risk early breast cancer treated in monarchE. San Antonio Breast Cancer Symposium 2020; 2020: PD2-01. Accessed March 16, 2021 at: https://www.abstractsonline.com/pp8/ \#!/9223/presentation/781

[84] Sparano JA, Gray RJ, Makower DF et al. Adjuvant Chemotherapy Guided by a 21-Gene Expression Assay in Breast Cancer. N Engl J Med 2018; 379 : 111-121

[85] Kalinsky K, Barlow WE, Meric-Bernstam F et al. First results from a phase III randomized clinical trial of standard adjuvant endocrine therapy (ET) \pm chemotherapy (CT) in patients (pts) with 1-3 positive nodes, hormone receptor-positive $(\mathrm{HR}+)$ and HER2-negative (HER2-) breast cancer (BC) with recurrence score (RS) <25: SWOG S1007 (RxPonder). San Antonio Breast Cancer Symposium 2020; 2020: GS3-00. Accessed March 16, 2021 at: https://www.abstractsonline.com/pp8/\#!/9223/ presentation/2794

[86] Kuhlen R, Schmithausen D, Winklmair C et al. Effekte von COVID-19Pandemie und Lockdown auf die Versorgung von Krankenhauspatienten. Dtsch Arztebl Int 2020; 117: 488-489

[87] von Lilienfeld-Toal M, Giesen N, Greinix H, Hein A, Hirsch HH, Na I-K, Sandherr M, Schanz U, Vehreschild J], Wörmann B. Coronavirus-Infektion (COVID-19) bei Patienten mit Blut- und Krebserkrankungen. 2021, Onkopedia Leitlinien - DGHO Deutsche Gesellschaft für Hämatologie und Medizinische Onkologie e.V. Accessed March 16, 2021 at: https://www. onkopedia.com/de/onkopedia/guidelines/coronavirus-infektion-covid19-bei-patienten-mit-blut-und-krebserkrankungen/@@guideline/html/ index.html

[88] de Azambuja E, Trapani D, Loibl S et al. ESMO Management and treatment adapted recommendations in the COVID-19 era: Breast Cancer. ESMO Open 2020; 5 (Suppl. 3): e000793

[89] Curigliano G, Cardoso M], Poortmans P et al. Recommendations for triage, prioritization and treatment of breast cancer patients during the COVID-19 pandemic. Breast 2020; 52: 8-16

[90] American Association of Clinical Oncology. ASCO Special Report: A Guide to Cancer Care Delivery During the COVID-19 Pandemic. 2020. Accessed March 16, 2021 at: https://www.asco.org/sites/new-www. asco.org/files/content-files/2020-ASCO-Guide-Cancer-COVID19.pdf

[91] Dowsett M, Ellis M], Dixon JM et al. Evidence-based guidelines for managing patients with primary ER+ HER2- breast cancer deferred from surgery due to the COVID-19 pandemic. NPJ Breast Cancer 2020; 6: 21

[92] Saini KS, Tagliamento M, Lambertini M et al. Mortality in patients with cancer and coronavirus disease 2019: A systematic review and pooled analysis of 52 studies. Eur J Cancer 2020; 139: 43-50

[93] Desai A, Gupta R, Advani S et al. Mortality in hospitalized patients with cancer and coronavirus disease 2019: A systematic review and metaanalysis of cohort studies. Cancer 2020. doi:10.1002/cncr.33386

[94] Epidemiology Working Group for NCIP Epidemic Response; Chinese Center for Disease Control and Prevention. [The epidemiological characteristics of an outbreak of 2019 novel coronavirus diseases (COVID-19) in China]. Zhonghua Liu Xing Bing Xue Za Zhi 2020; 41: 145-151

[95] Kuderer NM, Choueiri TK, Shah DP et al. Clinical impact of COVID-19 on patients with cancer (CCC19): a cohort study. Lancet 2020; 395: 19071918

[96] Lee JY, Kim HA, Huh K et al. Risk Factors for Mortality and Respiratory Support in Elderly Patients Hospitalized with COVID-19 in Korea. J Korean Med Sci 2020; 35: e223

[97] Bersanelli M. Controversies about COVID-19 and anticancer treatment with immune checkpoint inhibitors. Immunotherapy 2020; 12: 269-273 